\title{
ANALYYSIS OF MATCH PERFORMANCE OF FULL-BACKS FROM SELECTED EUROPEAN SOCCER LEAGUES
}

\author{
Marek Konefał, 1, A,C, D Paweł Chmura, , , A, C, D Marcin Andrzejewski, ${ }^{3, A, C, D}$ \\ Dawid Pukszta, ${ }^{1, A, B, D}$ Jan Chmura ${ }^{1, A, D, E}$
}

1 Department of Athletes' Motor Skills, University School of Physical Education, Wrocław, Poland

2 Department of Team Games, University School of Physical Education, Wrockaw, Poland

${ }^{3}$ Department of Recreation, University School of Physical Education, Poznań, Poland

A Study Design; ${ }^{\text {B }}$ Data Collection; ${ }^{\mathrm{C}}$ Statistical Analysis; ${ }^{\mathrm{D}}$ Manuscript Preparation; ${ }^{\mathrm{E}}$ Funds Collection

\author{
Address for corpespondence: \\ Paweł Chmura \\ University School of Physical Education, Department of Team Games \\ I.J. Paderewskiego 35,Wrocław, Poland \\ E-Mail: pawel.chmura@awf.wroc.pl
}

\begin{abstract}
Ahstract. The aim of the present study was the analysis of match activities of full-backs from selected European national soccer leagues. The study sample comprised 30 full-backs playing in the autumn round of the 2014/15 season from five European national top-tier leagues: English Premier League, Spanish Primera Division, German Bundesliga, Russian Priemjer Liga and Italian Serie A. The performance of full-backs (left-back and right-back) from each selected team was analyzed using a professional match analysis system OptaPro which tracks every possible type of ball touch and on the ball action in match covered by a rigid set of definitions. The data for analysis included the total number of passes, total number of crosses, and total number of ball touches performed by the fullbacks in three zones of the pitch: attack, midfield and defense. The study results showed that the full-backs from the Spanish Primera Division executed the highest number of passes and crosses as well as ball touches in the attack zone. They also performed the lowest number of passes in the midfield and defense zones, in which the highest percentage of passes was achieved by the full-backs from the German league teams. The study indicates that in modern soccer defenders must possess a high level of offensive skills that can be necessary in the last stage of a team's attack.
\end{abstract}

Key worlls: soccer, match performance, motor activity, kinematic analysis

\section{Introduction}

Rapid technological developments of the last years have made it possible to carry out accurate match analyses in various team sports. Advanced IT systems coupled with human intelligence are important research tools for examining multiple aspects of match-play. The Global Positioning System enables motor activity analysis of players in different playing positions, from different clubs or national leagues (Buchheit et al. 2010; Carling et al. 2008; Di Salvo et al. 2013). Differences in players' motor activity during matches were found between playing positions (defenders, midfielders, and forwards) as well as between particular types of any of these positions, e.g. 
full-backs or center backs, or center midfielders or side midfielders (Andrzejewski et al. 2012; Bradley et al. 2013; Carling et al. 2008). Although successful performance in soccer match-play requires superior levels of physical fitness to sustain a high work rate during matches, it is the technical and tactical skill level that usually separates successful soccer players and team performance during first division match play (Sforza et al. 1997).

Advanced match kinematic analysis systems allow for assessment of players' motor activity as well as tracking all actions during match play. All soccer playing positions, including the full-backs, require from players versatile motor preparation with a particular emphasis on endurance and speed skills (Andrzejewski et al. 2014). During a match full-backs in top national European leagues cover a mean distance between 10,650 m and 10,814 m, $11,063 \mathrm{~m}$ in the UEFA Europa League, and up to $11,410 \mathrm{~m}$ in the UEFA Champions League (Andrzejewski et al. 2014; Dellal et al. 2010; Dellal et al. 2011, Di Salvo et al. 2007; Djaoui et al. 2014). Depending on an assumed range of intensity ( $>23 \mathrm{~km} / \mathrm{h}$ ) full-backs may also cover a sprinting distance up to $402 \mathrm{~m}$ during match play. In terms of match-play actions, the mean number of ball touches by full-backs is from 41 to 59 in a match, the number of accurate passes is from 78 to $81 \%$, and the number of won one-on-one plays is from 54 to $56 \%$ (Stølen et al. 2005).

Differences between the motor activity profiles of players in various playing positions (Andrzejewski et al. 2012; Bradley et al. 2009) may indicate that similar differences may also occur in a quantitative analysis of match-play actions. Few authors have discussed the actions of full-backs during match play (Bradley et al. 2011; Carling 2010; Dellal et al. 2010; Lago-Peñas et al. 2011). In comparison with players in other positions in the French, Spanish and English leagues these authors noted that full-backs and center-backs lose the ball during a match significantly less often than players in other positions. Moreover, full-backs perform a significantly greater percentage of accurate passes than center-backs, and attain significantly shorter ball possession time than centermidfielders and forwards. This is related to the implementation of tactical tasks by players in these positions (Dellal et al. 2010; Dellal et al. 2011).

When analysing the physical performance of soccer players, the tactics of the game needs to be taken into account. The observed differences in physical demands for different playing positions may be partly explained by the different tactical roles involved in each position (Bradley et al. 2011). The positioning of players on the field and their offensive and defensive tasks are determined by, inter alia, the assumed team match formation (Bangsbo and Peterson 2000). In contemporary soccer there are various match formations which determine the motor activity profiles of players. In soccer the development of a team's game strategy should account for players' individual motor skills as well as technical and tactical skills (Carling 2011; Stølen et al. 2005). Studies have shown that the defenders in the 1-4-4-2 formation cover a significantly longer total distance than the defenders in the 1-4-5-1 and 1-4-3-3 match formations (Bradley et al. 2011). For the 1-4-4-2 formation the mean number of passes by full-backs in a match was 53 , for the 1-4-3-3 formation it was 54 , and for the 1-4-2-3-1 formation - 50. These differences were, however, statistically non-significant (Carling 2011).

The attainment of top sport results requires the knowledge about determinants of players' performance, in particular, the playing position. The majority of studies of European soccer leagues have used various systems of match analysis, and this thwarts any attempts of objective comparison of the obtained results. The application of the same match analysis system on players from different national leagues will allow for objective and reliable use of match analysis data in sport theory and practice (Drust et al. 2007). 
In modern soccer a high variability of full-backs' activities can be observed. Depending on the assumed game strategy, the full-backs perform more defensive or offensive tasks. The aim of the present study was an analysis of match-play actions of soccer full-backs from selected European national leagues.

\section{Methods}

The study sample comprised 30 full-backs from five European national leagues, who played the most full-time games in the 2014/15 autumn season. The analyzed matches included 78 matches of the English Premier League, 82 of the Spanish Primera Division, 61 of the German Bundesliga, 66 of the Russian Priemjer Liga, and 66 of the Italian Serie A. Three top table teams from each league at the end of the autumn round, which used 4 defenders in match formation, were considered. If a top team played its matches in a match formation with a different number of defenders, the next consecutive team from the table with 4 defenders was taken into account. For example, in the Spanish and Italian leagues, the top teams after the autumn round had to be replaced in the study with teams from the $4^{\text {th }}$ places. The performance of the left-back and the right-back from each team were analyzed. The research project has been approved by the local ethics committee.

The data for analysis was provided by an OptaPro match analysis system. Data from each match were taken in real time by three analysts (one for the home team, one for the away team, and one data verifier) and by an IT system tracking the players movements during match play (Liu et al. 2013). Every possible type of ball touch and on the ball action in match was covered by a rigid set of definitions which were recorded in the system. The analysts have undergone strict training to learn thoroughly about the definitions and to become familiar with the shortcut keys of different actions in the system before formally operating. During the training, an analyst is allowed to use "test servers" to imitate a live match situation (Liu et al. 2013; OPTA 2012). The analyzed match variables included the total number of passes, total number of crosses, and total number of ball touches in three zones of the playing field: attack, midfield and defense (each being a $1 / 3$ of the pitch length). According to the OPTA system definitions (Bateman 2010; OPTA 2012) a pass was understood as an intentional played ball from one player to another; a cross as any ball played into the opposition team's area from a wide position; and a touch as a sum of all events where a player touches the ball.

The statistical analysis was made with the use of Statistica 10.0. All variables were checked against normal distribution. The normality of distribution was checked with the Shapiro-Wilk test $(p \leq 0.05)$. Arithmetic means and standard deviations were calculated. To compare the data an ANOVA was used. To measure the statistical significance between the means Fisher's least significant difference (LSD) test was applied. Three levels of statistical significance were set at $p \leq 0.05, p \leq 0.01$, and $p \leq 0.001$.

\section{Resulls}

\section{Passes}

The data revealed statistically significant differences between the numbers of passes performed by full-backs from the Spanish and Russian national leagues ( $\leq \leq 0.001$ ), and from the Spanish and Italian leagues ( $p \leq 0.01)$ (Table 1). No significant differences in the number of passes were noted between the other leagues. 
Table 1. Total number of passes by full-backs from selected European national leagues and Fisher's LSD test results

\begin{tabular}{lccccc}
\hline \multicolumn{1}{c}{ National league } & English & Spanish & German & Russian & Italian \\
\hline $\mathrm{x} \pm \mathrm{SD}$ & $47.60 \pm 13.55$ & $51.85 \pm 20.87$ & $47.43 \pm 15.89$ & $42.84 \pm 13.07$ & $44.17 \pm 16.92$ \\
English & - & 0.103 & 0.952 & 0.085 & 0.214 \\
Spanish & 0.103 & - & 0.113 & $0.001^{* * *}$ & $0.005^{\star *}$ \\
German & 0.952 & 0.113 & - & 0.117 & 0.266 \\
Russian & 0.085 & $0.001^{* *}$ & 0.117 & - & 0.641 \\
Italian & 0.214 & $0.005^{* *}$ & 0.266 & 0.641 & - \\
\hline
\end{tabular}

Statistically significant differences: ${ }^{*}(p \leq 0.05) ;{ }^{* *}(p \leq 0.01) ;{ }^{* * *}(p \leq 0.001)$.

\section{Crosses}

The data revealed that a full-back in the Spanish league performed the mean number of $4.52 \pm 2.45$ crosses during a match. This number was significantly different from the mean numbers of crosses by full-backs from the English, German and Russian leagues ( $p \leq 0.001)$, and Italian league $(p \leq 0.01)$ (Table 2). The differences in the number of crosses by full-backs were significant between the Italian and German leagues ( $p \leq 0.001)$, and between the Italian and English leagues ( $p \leq 0.01$ ). The lowest level of statistical significance was found in the differences between the Russian and Italian leagues ( $p \leq 0.05$ ). The other differences were statistically non-significant (Table 2 ).

Table 2. Total number of crosses by full-backs from selected European national leagues and Fisher's LSD test results

\begin{tabular}{lccccc}
\hline \multicolumn{1}{c}{ National league } & English & Spanish & German & Russian & Italian \\
\hline $\mathrm{x} \pm \mathrm{SD}$ & $2.17 \pm 0.83$ & $4.52 \pm 2.45$ & $1.54 \pm 0.91$ & $2.32 \pm 0.95$ & $3.33 \pm 1.64$ \\
English & - & $0.001^{* * *}$ & 0.141 & 0.715 & $0.005^{* *}$ \\
Spanish & $0.001^{* * *}$ & - & $0.001^{* * *}$ & $0.001^{* * *}$ & $0.004^{* *}$ \\
German & 0.141 & $0.001^{* * *}$ & - & 0.079 & $0.001^{* * *}$ \\
Russian & 0.715 & $0.001^{* * *}$ & 0.079 & - & $0.019^{*}$ \\
Italian & $0.005^{* *}$ & $0.004^{* *}$ & $0.001^{* * *}$ & $0.019^{*}$ & - \\
\hline
\end{tabular}

Statistically significant differences: $\left.{ }^{*}(p \leq 0.05) ;{ }^{* *}(p \leq 0.01) ; * * * 0.001\right)$

\section{Ball touches in the attack, midfield and defense pitch zones}

The analysis of data showed that the full-backs from the German league performed the mean $32.14 \pm 9.39 \%$ ball touches in the defense zone per match (Figure 1). This is significantly different from the full-backs' results from the English, Russian and Italian leagues $(p \leq 0.05)$ and from the Spanish league ( $p \leq 0.001)$. The full-backs from the Spanish league featured the lowest number of ball touches in the defense zone $(24.61 \pm 9.84 \%)$, which was significantly lower than the number of ball touches by the full-backs from the Russian and Italian leagues ( $p \leq 0.05)$, and the English league $(p \leq 0.01)$. No other statistically significant differences in the number of ball touches were found.

In the midfield zone the number of ball touches by the full-backs from the Spanishleague $(41.79 \pm 8.94 \%)$ (Figure 2 ) wassignificantlylowerthan bytheircounterpartsfrom the English, Italianand Germanleagues ( $p \leq 0.001)$. In the German league the number of ball touches performed by the full-backs was $49.70 \pm 8.92 \%$, i.e. $4.63 \%$ significantly higher than 
in the Russian league ( $p \leq 0.01$ ), and $3.32 \%$ in the English league $(p \leq 0.05)$. Furthermore, the number of ball touches by the full-backs in the midfield zone in the Russian league was significantly lower than in the teams from the Italian league, and significantly higher than in the Spanish league $(p \leq 0.05)$. No other differences were statistically significant.

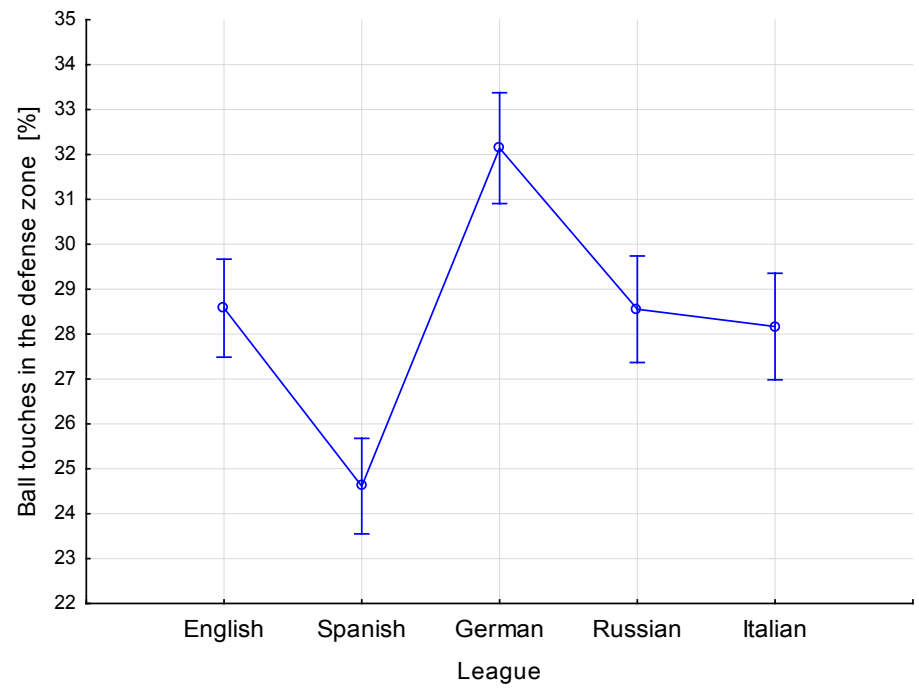

Figule 1. Mean number of ball touches in the defense zone by full-backs from selected European national leagues

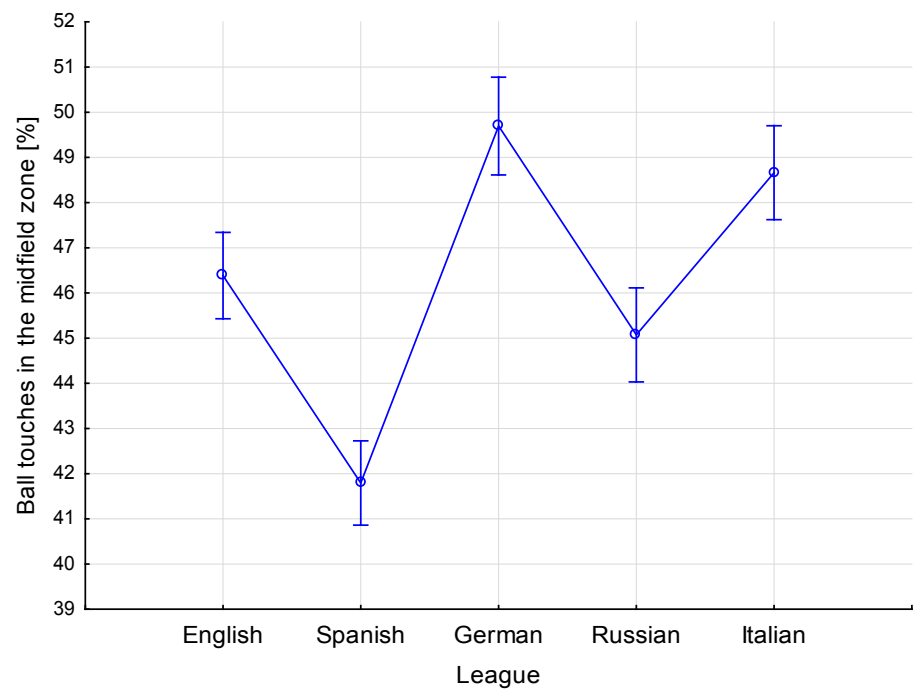

Figure 2. Mean number of ball touches in the midfield zone by full-backs from selected European national leagues 
The full-backs from the Spanish league had $33.59 \pm 10.98 \%$ ball touches in the attack zone (Figure 3), which was significantly higher than the number of ball touches by players from the other leagues $(p \leq 0.001)$. The differences in the number of ball touches in the attack zone were statistically significant $(p \leq 0.001)$ between the fullbacks from the German league, and full-backs from the English and Russian leagues. The number of ball touches in the attack zone by the full-backs from the Italian league was $23.17 \pm 8.85 \%$, and from the German league -18.16 $\pm 6.86 \%$. This was a statistically significant difference ( $p \leq 0.01)$.

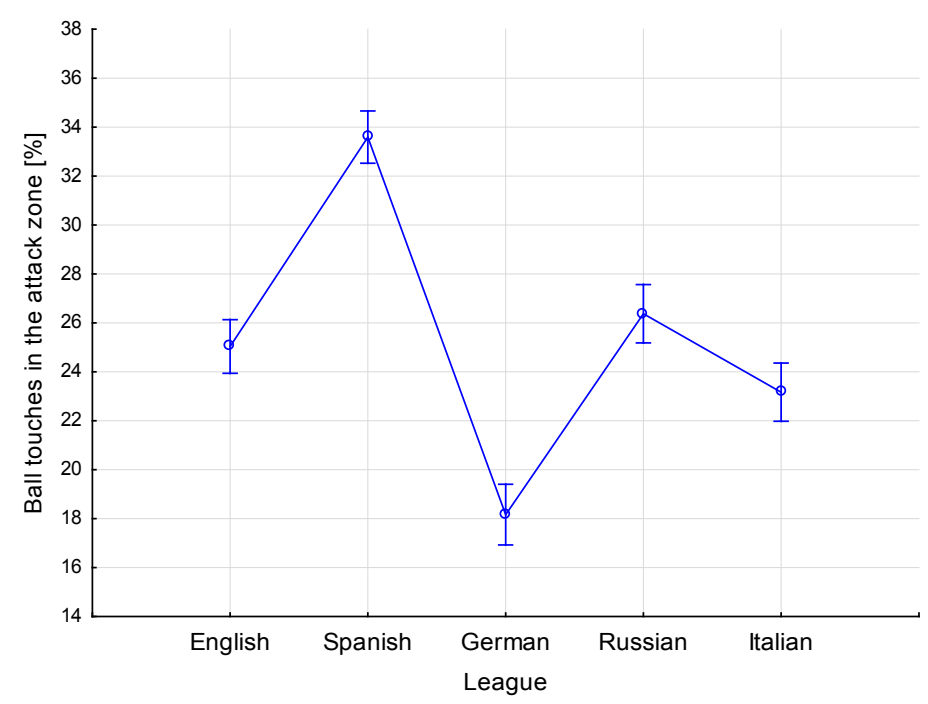

Figure 3. Mean number of ball touches in the attack zone by full-backs from selected European national leagues

\section{Discussion}

In the autumn round of the 2014/15 soccer season the full-backs from the Spanish league performed the greatest number of passes and crosses as well as ball touches in the attack zone, among all studied teams from the selected European national leagues. The Spanish league teams featured also the lowest number of passes in the midfield and defense zones. In these two zones the greatest percentage of passes was performed by players from the German league.

Dellal et al. (2011) found differences between the activity profiles (in motor skills and match performance) of full-backs from various national soccer leagues. Similar observations were made in the present study. We noted that the number of passes performed by full-backs from the Spanish league was significantly higher than the number of passes performed by their counterparts from the Italian and Russian leagues. The differences may result from the offensive playing style preferred by the Spanish teams, which can be illustrated by their greatest number of ball touches in the attack zone. The differences may be also due to the applied match strategy consisting of performing a large number of short passes in the opponent's half. Dellal et al. (2011) also revealed that the full-backs from the English league perform fewer passes per match, while possessing the ball for a significantly longer time than 
the full-backs from the Spanish league (59.76 s - English league full-backs, $54.40 \mathrm{~s}$ - Spanish league full-backs). This probably results from a greater number of one-on-one plays won by the Premier League defenders (Dellal et al. 2011). In terms of accuracy of passes, the highest percentage of accurate passes, i.e. $82.27 \%$, was attained by the Spanish league full-backs, and the lowest, i.e. $75.64 \%$ by the German league full-backs (unpublished data). The accuracy percentage of Europa League full-backs was 72\% (Andrzejewski et al. 2014), and of full-backs from top European teams 80\% (Dellal et al. 2011).

The results of the present study confirm the fact that the full-backs from the Spanish league do participate in numerous offensive actions of their teams, concluded with cross passes from a wide position. The ratio of the number of performed crosses to the total number of passes by full-backs from the Spanish league is 11.47. This is comparable with the result of full-backs from the Italian league (13.26), despite a significantly lower total number of passes in the studied teams from Serie A. This difference may have been caused by the relatively lower number of ball touches in the attack zone of the Italian league players. With similar numbers of passes by full-backs from the Italian and Russian leagues, the Premjer Liga full-backs attained the ratio of 18.46, which indicates lower contribution of the Russian league full-backs to their teams' offensive actions concluded with cross passes from a wide position.

The analysis of the number of ball touches in different pitch zones showed that the full-backs from the Spanish league demonstrated the most offensive tactics. They possessed the ball for the shortest time and covered a significantly shorter distance with high intensity than the full-backs from the Premier League (Dellal et al. 2011). Despite these results they performed a greater number of passes, crosses and ball touches in the attack zone. The main reason for this could be ball possession time by the top Primera Division teams in the opposing team's half. The number of their ball touches in the attack zone does, in fact, correspond to the total number of passes in a game. The full-backs from the German league executed the biggest number of ball touches in all analyzed matches, in the defense and midfield zones. This figure was most likely determined by the high number of inaccurate passes, which did not permit the team to advance to the attack zone since it lost ball possession (unpublished data). This is confirmed by the small number of executed cross passes by the German league full-backs and by only $18.16 \%$ of ball touches in the attack zone of the field.

The execution of the analyzed match actions depends to a great extent on the players' level of motor preparation. The analysis of motor activity profiles of players during a match revealed significant differences between players in different positions. In defensive positions, the full-backs cover the longest distance and feature the highest accuracy of passes (Barros et al. 2007; Clemente et al. 2013; Di Salvo et al. 2007). The majority of studies of full-backs from various European national leagues did not reveal significant differences in their motor activity during matches (Barros et al. 2007; Dellal et al. 2010; Dellal et al. 2011; Di Salvo et al. 2007; Mohr et al. 2003), however, such differences were noted in the Europa League (Andrzejewski et al. 2014).

According to the UEFA Club Ranking (June 2015) the top five European teams include three teams from the Spanish Primera Division (1st, 2nd and 5th positions). These standings are calculated on the basis of results of the teams attained in European cup matches, which means that the ranked teams are not only the leading teams in their top national leagues but also in the UEFA Champions League or the UEFA Europa League. The other studied leagues are also top European national leagues, however, not all the analyzed teams were highly positioned in the club ranking. It can be assumed that the numbers of passes, crosses and active involvement of full-backs in the attack zone contribute to the attainment of good sports results by a team. In order to more precisely determine 
the differences in the match performance of full-backs from various European national leagues, studies should be carried out on a greater number of teams from each league for much longer periods of time.

\section{Conclusions}

1. Among the studied European national leagues the full-backs from the Spanish Primera Division contribute the most to the offensive play of their teams. This is evidenced by the highest number of passes, crosses and ball touches in the attack zone of the playing field performed by the Spanish league full-backs.

2. The training process of full-backs must involve development of offensive playing actions, in particular, cross passes.

3. The selection process of full-backs must account for their tasks within the team's general match strategy. In modern soccer a full-back must possess a high level of playing skills necessary for team actions in the final phase of attacks.

4. The effective offensive play of full-backs may greatly affect the results of top-level soccer competitions, which is evidenced by the top positions of teams from the Spanish national league in the UEFA Club Ranking.

\section{Reterencees}

Andrzejewski M., Chmura J., Pluta B., Kasprzak A. Analysis of motor activities of professional soccer players. J Strength Cond Res. 2012; 26 (6): 1481-1488.

Andrzejewski M., Chmura J., Pluta B. Analysis of motor and technical activities of professional soccer players of the UEFA Europa League. Int J Perform Anal Sport. 2014; 14 (2): 504-523.

Bangsbo J., Peterson B. Soccer systems and strategies. Human Kinetics, Champaign, IL 2000.

Barros R.L., Misuta M.S., Menezes R.P., Figueroa P.J., Moura F.A., Cunha S.A., Anido R., Leite, N.J. Analysis of the distances covered by first division Brazilian soccer players obtained with an automatic tracking method. J Sports Sci Med. $2007 ; 6$ (2): $233-242$.

Bateman R. Opta's Event Definitions. OPTASPORTS, 2010. Retrieved: http://optasports.com/news-area/blog-optas-event-definitions. aspx.

Bradley P.S., Sheldon W., Wooster B., Olsen P., Boanas P., Krustrup P. High-intensity running in English FA Premier League soccer matches. J Sports Sci. 2009; 27 (2): 159-168.

Bradley P.S., Carling C., Archer D., Roberts J., Dodds A., Di Mascio M., Paul D., Diaz A.G., Peart D., Krustrup, P. The effect of playing formation on high-intensity running and technical profiles in English FA Premier League soccer matches. J Sports Sci. 2011; 29 (8): 821-830.

Bradley P.S., Carling C., Gomez Diaz A., Hood P., Barnes C., Ade J., Boddy M., Krustrup P., Mohr M. Match performance and physical capacity of players in the top three competitive standards of English professional soccer. Hum Mov Sci. $2013 ; 32$ (4): $808-821$.

Buchheit M., Mendez-Villanueva A., Simpson B.M., Bourdon P.C. Match running performance and fitness in youth soccer. Int J Sports Med. 2010; 31 (11): 818-25.

Carling C., Bloomfield J., Nelsen L., Reilly T. The Role of Motion Analysis in Elite Soccer: Contemporary Performance Measurement Techniques and Work Rate Data. Sports Med. 2008; 38 (10): 839-862.

Carling C. Analysis of physical activity profiles when running with the ball in a professional soccer team. J Sports Sci. 2010 ; 28 (3): 319-326.

Carling C. Influence of opposition team formation on physical and skill-related performance in a professional soccer team. Eur J Sports Sci. 2011; 11 (3): 155-164.

Clemente F.M., Couceiro M.S., Lourenço Martins F.M., Ivanova M.O., Mendes R. Activity Profiles of Soccer Players During the 2010 World Cup. Hum Kinet. 2013; 38: 201-211.

Dellal A., Wong D.P., Moalla W., Chamari K. Physical and technical activity of soccer players in the French First League - with special reference to their playing position. Int Sportmed J. 2010; 11 (2): 278-290. 
Dellal A., Chamari K., Wong D.P., Ahmaidi S., Keller D., Barros R., Carling C. Comparison of physical and technical performance in European soccer match-play: FA Premier League and La Liga. Eur J Sports Sci. 2011; 11 (1): 51-59.

Di Salvo V., Baron R., Tschan H., Calderon Montero F., Bachl N., Pigozzi F. Performance Characteristics According to Playing Position in Elite Soccer. Int J Sports Med. 2007; 28 (3): 222-227.

Di Salvo V., Pigozzi F., González-Haro C., Laughlin M.S., De Witt J.K. Match performance comparison in top English soccer leagues. Int J Sports Med. 2013; 34 (6): 526-532.

Djaoui L., Wong del P., Pialoux V., Hautier C., Da Silva C.D., Chamari K., Dellal A. Physical Activity during a Prolonged Congested Period in a Top-Class European Football Team. Asian J Sports Med. 2014; 5 (1): 47-53.

Drust B., Atkinso G., Reilly T. Future Perspectives in the Evaluation of the Physiological Demands of Soccer. Sports Med. $2007 ; 37$ (9): 783-805.

Liu H., Hopkins W., Gómez M.A., Molinuevo J.S. Inter-operator reliability of live football match statistics from OPTA Sportsdata. Int J Perform Anal Sport. 2013; 13 (3): 803-821.

Lago-Peñas C., Casais L., Dellal A., Rey E., Domínguez E. Anthropometric and physiological characteristics of young soccer players according to their playing positions: relevance for competition success. J Strength Cond Res. 2011; 25 (12): 3358-3367.

Mohr M., Krustrup P., Bangsbo J. Match performance of high-standard soccer players with special reference to development of fatigue. J Sports Sci, 2003; 21 (7): 519-528.

OPTA System. Definiciones OPTA and Pack Training 2012/13. OPTASPORTS, 2012; Sportsdata.

Sforza C., Michielon G., Grassi G., Alberti G., Ferrario V.F. Bivariate analysis of the repeatability of football offensive schemes. In: Science and Football III. Proceedings of the Third World Congress of Science and Football, eds. T. Reilly, J. Bangsbo, M. Hughes, E. \& F. N. Spon, London 1997: 233-239.

Stølen T., Chamari K., Castagna C., Wisløff U. Physiology of Soccer: An Update. Sports Med. 2005; 35 (6): 501-536.

Wong D. Characteristics of World Cup soccer players. Soccer Journal. 2008; 53 (1): 57-62.

Cite this anticle as: Konefał M., Chmura P., Andrzejewski M., Pukszta D., Chmura J. Analysis of Match Performance of Full-backs from Selected European Soccer Leagues. Central European Journal of Sport Sciences and Medicine. 2015; 11 (3): 45-53. 
